\title{
Effect of the Canary Islands in the blockage and mixing of the North Atlantic eastern water masses
}

\author{
F. Machín ${ }^{1}$ and J. L. Pelegrí ${ }^{1}$ \\ Received 2 November 2005; revised 3 January 2006; accepted 5 January 2006; published 18 February 2006.
}

[1] We apply an inverse model to a hydrographic cruise that completely closes the Canary Islands to investigate their effect on the water masses transports. Most central waters are transported south between the eastern islands and the African coast, with $2.5 \mathrm{~Sv}$ out of a total of $3.5 \mathrm{~Sv}$. Intermediate waters are effectively blocked by the islands passages, with Mediterranean/Antarctic waters predominantly found north/south of the islands, and most deep waters loop around the archipelago plateau. A process model upholds the existence of intense two-way exchange between central and intermediate waters along the eastern passage, with vertical velocities of order $10^{-5} \mathrm{~m} \mathrm{~s}^{-1}$. Citation: Machín, F., and J. L. Pelegrí (2006), Effect of the Canary Islands in the blockage and mixing of the North Atlantic eastern water masses, Geophys. Res. Lett., 33, L04605, doi:10.1029/2005GL025048.

\section{Introduction}

[2] The eastern boundary of the North Atlantic off NW Africa is a complex region resulting from the interplay of several forcing mechanisms. In the top 600 or $700 \mathrm{~m}$ the southward flowing Canary Current (CC), composed of upper-thermocline North Atlantic Central Waters (NACW), is the subtropical gyre eastern boundary current [Stramma, 1984]. This current interacts with the coastal upwelling system [Pelegrí et al., 2005], that occurs all year long between the Strait of Gibraltar and Cape Blanc, and is conditioned by an outflow of about $1 \mathrm{~Sv}$ into the Mediterranean [Candela, 2001]. At intermediate levels we find relatively fresh $(S<35.4)$ waters of southern origin, usually identified as Antarctic Intermediate Waters (AAIW) [Hughes and Barton, 1974]. High salinity $(S=36.5)$ Mediterranean Water (MW) is found as a wide wedge at some $1000 \mathrm{~m}$ north of the Canary Islands [e.g., Pérez et al., 2001]. Further below we find the relatively fresh $(S<35.0)$ and cold $\left(\theta<4^{\circ} \mathrm{C}\right)$ North Atlantic Deep Water (NADW) [Pérez et al., 2001]. The advance of all these water masses is greatly conditioned by the presence of the Canary Archipelago that stretches zonally some $550 \mathrm{~km}$ west of the African coast (Figure 1). The archipelago is located over a plateau some $2500 \mathrm{~m}$ deep and has four main passages, the easternmost between the islands and the African coast (Lanzarote Passage, hereafter LP). The two western passages reach the plateau itself but the two eastern ones have sills no deeper than some $1200 \mathrm{~m}$.

\footnotetext{
${ }^{1}$ Institut de Ciències del Mar, Consejo Superior de Investigaciones Científicas, Barcelona, Spain.
}

Copyright 2006 by the American Geophysical Union. 0094-8276/06/2005GL025048
[3] Recent studies have confirmed that the $\mathrm{CC}$ is intimately connected with the coastal upwelling region off NW Africa, with deep-ocean upper-thermocline waters flowing into the continental slope region [Pelegri et al., 2005; Machín et al., 2006, and references therein]. This results in an eastern, or near-shore, branch of the $\mathrm{CC}$ that on average accommodates $1 \mathrm{~Sv}$ of southward flow though in summer it reaches 2.4 Sv [Machín et al., 2006], hereafter to be identified as Canary Upwelling Current (CUC). The CUC increases in summer and fall as a result of the trade winds, such that by late fall it becomes unstable and detaches from Cape Guir $\left(32^{\circ} \mathrm{N}\right)$ to merge with the offshore branch of the CC. This opens the eastern passages to the winter surface manifestation of the poleward undercurrent, that runs along the continental slope centered at depths of some $300 \mathrm{~m}$ [Barton, 1989]. Because of its southern origin the poleward undercurrent favors the along-slope northward penetration of the underlying AAIW [Hughes and Barton, 1974]. By early spring the CUC decreases in intensity and returns to an along-slope southward path, with a transport of $1.9 \mathrm{~Sv}$ [Machin et al., 2006], and the poleward flow becomes, once again, an undercurrent.

[4] Here we use a cruise that draws a closed box around the Canary Islands (Figure 1) to examine how they modulate the flow of water masses. We obtain the transports using an inverse model, with a careful selection of the reference level. The data and model results are also used to assess the intensity of vertical mixing between NACW and AAIW in LP.

\section{Data}

[5] The hydrographic data were collected between 2 and 17 March 1999 during Cruise 249 on board R/V Poseidon. Figure 2 shows the distribution of neutral density $\gamma_{n}$ and salinity $S$ along all transects. Figure 2a reveals the upperthermocline isoneutrals approaching the sea surface at stations close to the African coast, and some steep level changes within NADW in the southern transect. Figure $2 b$ shows $S$ as a function of $\gamma_{n}$. Potential temperature $\theta$ (not shown) and $S$ are quite constant at NACW $\left(\gamma_{n}<27.25\right)$ and NADW $\left(\gamma_{n}>27.9\right)$ levels, but not so at intermediate levels $\left(27.25<\gamma_{n}<27.9\right)$ because of the presence of AAIW in the southern transect and some MW in the northern transect (as revealed by $\theta-S$ diagrams, not shown).

[6] Surface wind stress have been obtained from the Centre ERS d'Archivage et de Traitement (CERSAT) with a $1^{\circ} \times 1^{\circ}$ spatial resolution. Figure 1 shows the average wind stress field during the cruise, with upwelling-favorable conditions. Five moorings were deployed in LP, from 1 January 1997 to 31 December 1998 [Knoll et al., 2002]. Hernández-Guerra et al. [2003] have used those data to 


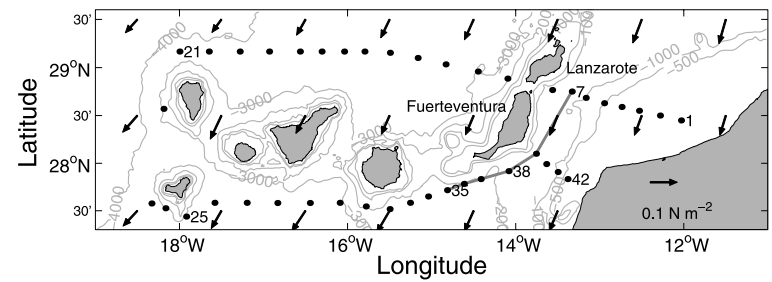

Figure 1. CTD stations and the surface wind stress field. The grey line indicates the channel section.

estimate the total flux through the passage by means of one single mooring, which remained beyond 1 January 1999.

\section{Inverse Model}

[7] The basic assumption of the inverse box model is that properties must be conserved within a close volume of seawater. This must apply to the whole box and to each of the 12 isoneutral layers used to divide the water column (Figure 2a). The conservation equations are:

$$
\int \rho C\left(v_{r}+b\right) d x d y+C T_{E}=0
$$

where $v_{r}$ is the relative geostrophic velocity, $b$ is the reference level velocity, $\rho$ is density, and $T_{E}$ is the watermass Ekman transport. The mass, salinity, and heat equations are obtained letting $C$ to be 1 , salinity, and heat content, respectively. $T_{E}$ is composed of two terms, $T_{E_{\text {sat }}}$ and $\Delta T_{E}$, the first one estimated from the wind stress field and the second one adjusted by the model. The velocities $v_{r}$ are evaluated from the hydrographic data (excluding station 39) while the $b$ are determined by the inverse model. Salt and heat are introduced as anomaly equations to avoid redundancy with the mass equations. Salt anomaly is assumed to be conserved in all layers while heat anomaly conservation only holds for deep layers. The fluxes in the channel between the islands and the African coast are constrained by direct current-meter measurements [Machin et al., 2006].

[8] The resulting system consists of 31 equations (13 for mass, 12 for salt anomaly, 4 for heat anomaly, and 2 for



Figure 2. (a) Neutral density as a function of depth, note the change in the vertical axis below $650 \mathrm{~m}$. The isoneutrals shown correspond to those used in the inverse model. (b) Salinity as a function of neutral density.

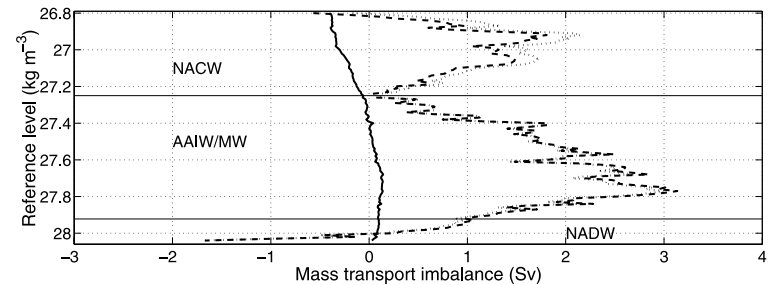

Figure 3. Mass transport imbalances as a function of reference level, before (dashed) and after (solid) the inversion. The mass transport imbalance correction is also shown (dotted).

current-meter fluxes) and 42 unknowns (39 reference-level velocities, and 3 Ekman transport adjustments). A GaussMarkov estimator deals with such undetermined systems, obtaining a solution consistent with some additional information on the uncertainties in both equations and unknowns. As a measure of uncertainty in the referencelevel velocity we use the observed long-term variability in the Canary Basin [Müller and Siedler, 1992], while for the Ekman adjustments we use the wind stress error given by CERSAT. An objective measure for the equations uncertainties is obtained by relating the covariance of the equations noise with the covariance of the unknowns [Machin et al., 2006].

[9] To explore the sensitivity of the solution to changes in the reference-level we have computed the total mass transport imbalances for reference levels spanning the whole water column, every $0.01 \gamma_{n}$-units from 26.8 to 28.04 . Figure 3 shows these imbalances when $b=0$ and after the inverse model introduces non-zero $b$ values. Before the inversion the imbalance is minimized near isoneutrals 27.25 and 28.0, i.e., in the transition layers between water masses. After the inversion the imbalance is very much reduced for any reference level and tends to zero for isoneutrals deeper than about 27.25. The imbalance correction is minimum at 27.25 , meaning that at this level less energy is added to the system to satisfy the constraints. We choose this isoneutral as the reference-level for the following calculations.

[10] Figure 4 presents the water transports for the central (layers 1 to $3, \gamma_{n}<27.25$ ), intermediate (layers 4 to 7 , $27.25<\gamma_{n}<27.92$ ), and deep (layers 8 to $12, \gamma_{n}>27.92$ ) water masses. The transports in layers 4 through 7 represent upper estimates for the intermediate waters, as AAIW (and

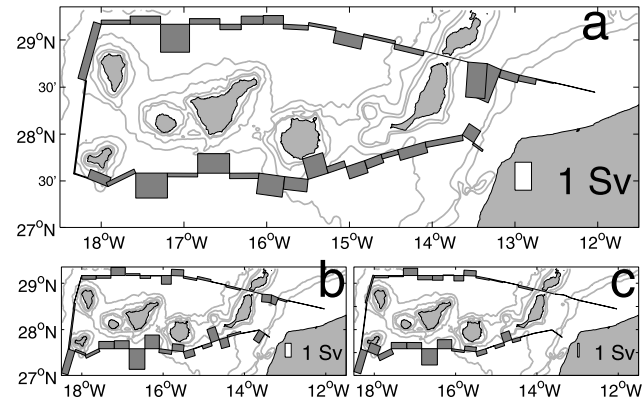

Figure 4. Mass transport in layers (a) 1 to 3 (NACW), (b) 4 to 7 (AAIW), and (c) 8 to 13 (NADW), as obtained from the inverse model with a reference level at $\gamma_{n}=27.25$. 




Figure 5. Absolute geostrophic velocities $\left(\mathrm{cm} \mathrm{s}^{-1}\right)$ near the African coast in the northern and southern sections. The shading emphasizes the vertical flow structure: $v \leq$ $-4 \mathrm{~cm} \mathrm{~s}^{-1}$ (dark), $-4 \mathrm{~cm} \mathrm{~s}^{-1}<v<0 \mathrm{~cm} \mathrm{~s}^{-1}$ (light), $v>$ $0 \mathrm{~cm} \mathrm{~s}^{-1}$ (no shading). A schematic interpretation of the circulation patterns is included, with solid and dashed lines denoting flow lines for NACW and AAIW, respectively. Station numbers as in Figure 1, dotted lines correspond to neutral contours in Figure 6.

MW in some northern stations) do not occupy this water stratum for all stations. Calculations using only layer 5 show the same patterns but transports are typically reduced to half the values in Figure $4 \mathrm{~b}$. The transports reflect a predominant southward flow within all water masses, but with the presence of complex island-induced recirculation patterns [Arístegui et al., 1994].

[11] Figure 5 shows the absolute velocity fields, as predicted by the model, for shorter sections near the continental slope (in LP, Figure 1). The shading emphasizes the vertical flow structure, notice that the inverse model has introduced non-zero velocities at $\gamma_{n}=27.25$. NACW flows south in the whole northern section and in the southern section except near the African coast. AAIW flows north only in the central portion of the southern section, and is nearly stagnant in the northern section. The observed patterns may be interpreted as the result of cyclonic recirculations within LP.

\section{Mixing Model}

[12] Let us examine the $S$ and $\theta$ distributions in LP and investigate whether these may respond to intensified vertical mixing between NACW and AAIW. We imagine a twolayer structure with NACW overlying AAIW. The available sampling allows us to define a hypothetical flow path conformed by stations $7,39,38,37,36$, and 35 (hereafter channel section), that follows along the western portion of this passage (Figures 1 and 5). Let us assume steady state, the salt balance for the top layer is (Figure 6)

$$
\frac{d\left(v_{1} S_{1} h_{1}\right)}{d y}-w_{2} S_{2}+w_{1} S_{1}=0
$$

where $v(y)$ is the along-section velocity, $h(y)$ is the layer thickness, $S(y)$ is a mean layer salinity, and subindexes 1 and 2 identify the top and bottom layers. Notice we have assumed that epipycnal transfer is dominated by the alongsection flow, i.e., we have neglected epipycnal diffusion and cross-flow. The vertical (diapycnal as it implies salt transfer) velocity is $w_{1}$ for water transfer from the top to the bottom layers, and $w_{2}$ for the opposite. In equation (2) the sign of $v$ is implicit but notice we ask for both $w_{1}$ and $w_{2}$ to be positive.
[13] Integrating (2) between $y_{a}$ and $y_{b}$ leads to

$$
\Phi_{1 b}-\Phi_{1 a}-w_{2} \Sigma_{2}+w_{1} \Sigma_{1}=0
$$

where $\Phi_{1} \equiv v_{1} h_{1} S_{1}, \Sigma_{1}=\int_{y_{a}}^{y_{b}} S_{1} d y$, and $\Sigma_{2}=\int_{y_{a}}^{y_{b}} S_{2} d y$. Repeating the above procedure for the bottom layer gives

$$
\Phi_{2 b}-\Phi_{2 a}-w_{1} \Sigma_{1}+w_{2} \Sigma_{2}=0
$$

where $\Phi_{2} \equiv v_{2} h_{2} S_{2}$. Combination of (3) and (4) shows

$$
\Phi_{2 b}-\Phi_{2 a}=-\left(\Phi_{1 b}-\Phi_{1 a}\right)
$$

This expression confirms that diapycnal salt exchange is the result of convergence/divergence in the epipycnal salt transport within each layer.

[14] Expressions (3) and (4) do not allow us to calculate $w_{1}$ or $w_{2}$. Hence, we assume that mixing is due to vertical shear that results in two-way exchange, i.e., both layers have equal level of turbulence so there is no preferential one-way entrainment, or $w_{1}=w_{2} \equiv w$. This vertical velocity may be estimated as either one of the following expressions

$$
w_{\text {top }}=\frac{\Phi_{1 b}-\Phi_{1 a}}{\Sigma_{2}-\Sigma_{1}} ; \quad w_{b o t}=\frac{\Phi_{2 b}-\Phi_{2 a}}{\Sigma_{1}-\Sigma_{2}}
$$

Differences between $w=w_{\text {top }}$ and $w=w_{\text {bot }}$ indicate the degree of approximation in equation (5).

[15] An effective vertical diffusion coefficient may be estimated from equations (6) as

$$
w\left(\Sigma_{2}-\Sigma_{1}\right) \cong-K \frac{S_{1}-S_{2}}{\delta z}\left(y_{b}-y_{a}\right)
$$

where $\delta z$ is the distance between the center points of layers 1 and 2 , and $S_{1}$ and $S_{2}$ are the salinities at some midpoint within those layers (Figure 6). The whole procedure is repeated for heat content (essentially $\theta$ ), leading to independent estimates for all vertical mixing variables.

[16] Figure 7a shows the changes in $S$ and $\theta$ over selected isoneutrals along the channel section which allow us to define the model layers (Figure 6). The top and bottom isoneutrals characterize the (slowly changing) NACW and AAIW layers (though the latter water mass shows substantial variability), while the middle isoneutrals characterize the top and bottom layers (affected through diapycnal mixing) in our model. Notice that the interface between

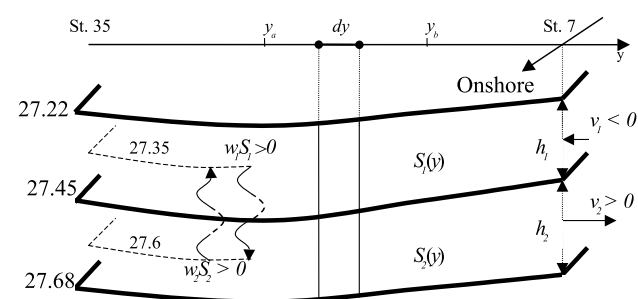

Figure 6. Schematic illustration of the idealized two-layer mixing model. The upper and lower layers respectively characterize NACW and AAIW undergoing intense diapycnal mixing. 


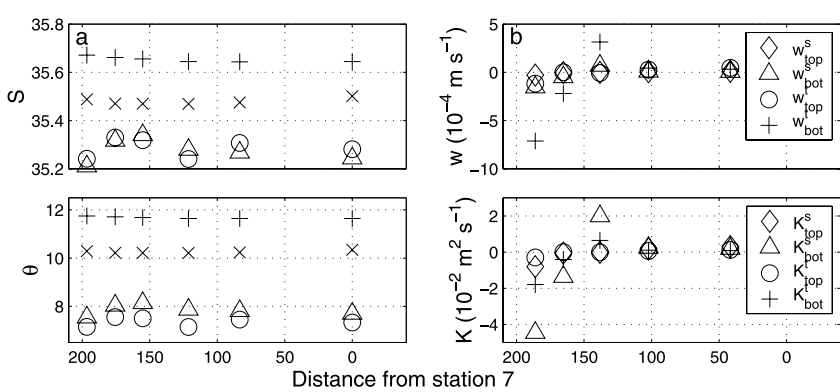

Figure 7. (a) Salinity and potential temperature along the channel section on isoneutrals 27.22(+), 27.35( $\times), 27.6(\triangle)$ and 27.68(o). (b) Vertical velocities and diffusion coefficients from the mixing model.

NACW and AAIW appears to be located close to $\gamma_{n}=27.45$ in this region, i.e., near the lower interface of layer 4 . In the top layer both $S$ and $\theta$ decrease toward a minimum near $150 \mathrm{~km}$ (approaching the bottom layer values) beyond which both variables again increase, the opposite for the bottom layer. Our interpretation is that these values arise as the result of vertical mixing within the passage.

[17] The layer salinities and thicknesses are available from the data. The difficulty is how to estimate the alongsection velocity, as most values in Figure 5 are normal to the channel section. Two exceptions are the velocities near stations 7 and 38. The former is indeed an along-section velocity and the latter, as station 39 is not used in the inverse model, is a good estimate of the along-channel flow. Further, because of the westward orientation of the island (and the channel section) we assume that the velocities near stations 37 to 35 (Figure 5) do reflect typical along-channel values in the western portion of the passage. Based on these data we idealize the two-layer structure shown in Figure 6 as having southward flows of $0.04 \mathrm{~m} \mathrm{~s}^{-1}$ in the upper layer and $0.03 \mathrm{~m} \mathrm{~s}^{-1}$ in the lower layer.

[18] Figure $7 \mathrm{~b}$ shows the model results, the variables with superindexes $\mathrm{s}$ and $\mathrm{t}$ representing those results obtained from the $S$ and $\theta$ data, respectively. In the northern portion of the channel, up to $150 \mathrm{~km}$ from station 7 , we find positive vertical velocities of $\mathrm{O}\left(10^{-5} \mathrm{~m} \mathrm{~s}^{-1}\right)$ and equivalent vertical diffusion coefficients of $\mathrm{O}\left(10^{-3} \mathrm{~m}^{2} \mathrm{~s}^{-1}\right)$. Salt/heat convergence in the upper layer provides for salt/heat divergence in the lower layer, which results in the observed anomalies. This is not true in the southern end of the channel, where it opens wide and lateral inflow may dominate the salt and heat balances. In this region the model gives unrealistic negative vertical velocities and diffusion coefficients.

\section{Conclusions}

[19] The Canary Islands act as a major obstacle to the eastern boundary flow at all water levels. In the deep layers $\left(\gamma_{n}>27.92\right.$, below about $\left.1400 \mathrm{~m}\right)$ NADW flows south through the northern section $(2.0 \mathrm{~Sv})$ and east through the western section $(0.5 \mathrm{~Sv})$. This flow, when occurring between about 1400 and $2500 \mathrm{~m}$, finds its way through the western passages. However, below $2500 \mathrm{~m}$ (the depth of the archipelago plateau) NADW loops around the plateau to enter the southern archipelago waters (Figures 2a and 4c).
At intermediate levels $\left(27.25<\gamma_{n}<27.92\right.$, roughly between 600 and $1400 \mathrm{~m}$ ) the islands intercept both MW, only found in the northern transect, and AAIW, dominant in the southern transect but less prominent in the northern one (Figure 2b). The northern transect displays relatively small water transports while the southern transect shows much greater values in and out the plateau (Figure $4 \mathrm{~b}$ ). In the near-surface layers $\left(\gamma_{n}<27.25\right.$, depths less than about $600 \mathrm{~m}) 2.5 \mathrm{~Sv}$ of NACW find their way through LP, in contrast with only $1.0 \mathrm{~Sv}$ that flow through the other three passages (Figure 4a).

[20] The channeling effect and large-scale/mesoscale recirculations induced by the islands are certain to increase the epipycnal (near-horizontal) diffusion, as suggested by large eddy kinetic energies [e.g., Käse et al., 1985]. The islands, however, also have a major effect on the diapycnal mixing between adjacent water masses, specially between NACW and AAIW. Such mixing results in NACW freshening as it moves south and AAIW becoming more salty as it recirculates through the passages. A simple model gives two-way exchange diapycnal velocities $\mathrm{O}\left(10^{-5} \mathrm{~m} \mathrm{~s}^{-1}\right)$, or vertical eddy diffusion coefficients $\mathrm{O}\left(10^{-3} \mathrm{~m}^{2} \mathrm{~s}^{-1}\right)$. These large values are necessary to sustain the observed property changes in such short distances. Gradient Richardson numbers calculated using geostrophic velocities are supercritical, well above 10 , so they may precondition but are not responsible for the intense mixing. Additional ageostrophic shear-flow, originated at the nearby island and continental slopes, is likely to sustain the observed mixing.

[21] Acknowledgments. We thank the Irish Marine Data Center and CERSAT for making available the hydrographic and wind stress data, respectively, and two anonymous reviewers who kindly suggested comments that helped to improve the final state of our manuscript. This work has been funded by the Spanish government through Project CANOA (CTM2005-00444/MAR) and by European Union through projects CANIGO (MAS3-CT96-0060) and OASIS (EVK3-CT-200200073-OASIS).

\section{References}

Arístegui, J., P. Sangrà, S. Hernández-León, M. Cantón, A. HernándezGuerra, and J. Kerling (1994), Island-induced eddies in the Canary Islands, Deep Sea Res., Part I, 41(10), 1509-1525.

Barton, E. (1989), The poleward undercurrent of the eastern boundary of the subtropical North Atlantic, in Poleward Flows Along Eastern Ocean Boundaries, vol. 34, edited by S. Neshyba et al., pp. 82-95, Springer, New York.

Candela, J. (2001), Mediterranean water and global circulation, in Ocean Circulation and Climate, edited by G. Siedler, J. Church, and J. Gould, pp. 419-429, Elsevier, New York.

Hernández-Guerra, A., E. Fraile, R. Borges, F. López-Laatzen, P. Vélez, G. Parrila, and T. Müller (2003), Transport variability in the Lanzarote Passage (Eastern Boundary Current of the North Atlantic Subtropical Gyre), Deep Sea Res., Part I, 50, 189-200.

Hughes, P., and E. Barton (1974), Stratification and water mass structure in the upwelling area off northwest Africa in April/May 1969, Deep Sea Res., 21, 611-628.

Käse, R., W. Zenk, T. Sanford, and W. Hiller (1985), Currents, fronts and eddy fluxes in the Canary Basin, Prog. Oceanogr., 14, 231-257.

Knoll, M., A. Hernández-Guerra, B. Lenz, F. López-Laatzen, F. Machín, T. Müller, and G. Siedler (2002), The Eastern Boundary Current system between the Canary Islands and the African Coast, Deep Sea Res., Part II, 49, 3427-3440.

Machín, F., A. Hernández-Guerra, and J. L. Pelegrí (2006), Mass fluxes in the Canary Basin, Prog. Oceanogr., in press.

Müller, T., and G. Siedler (1992), Multi-year current time series in the eastern North Atlantic Ocean, J. Mar. Res., 50, 63-98.

Pelegrí, J. L., J. Arístegui, L. Cana, M. González-Dávila, A. HernándezGuerra, S. Hernández-León, A. Marrero-Díaz, M. Montero, P. Sangrà, and M. Santana-Casiano (2005), Coupling between the open ocean and 
the coastal upwelling region off northwest Africa: Water recirculation and offshore pumping of organic matter, J. Mar. Syst., 54, 3-37.

Pérez, F. F., L. Mintrop, O. Llinás, M. González-Dávila, C. Castro, M. Álvarez, A. Körtzinger, M. Santana-Casiano, M. Rueda, and A. Ríos (2001), Mixing analysis of nutrients, oxygen and inorganic carbon in the Canary Islands region, J. Mar. Syst., 28, 183-201.
Stramma, L. (1984), Geostrophic transport in the warm water sphere of the eastern subtropical North Atlantic, J. Mar. Res., 42, 537-558.

F. Machín and J. L. Pelegrí, ICM-CSIC, Passeig Marítim de la Barceloneta 37-49, E-08003 Barcelona, Spain. (fmachin@icm.csic.es) 